\title{
Reflection of Social and Cultural Features in the Names of Stones and Minerals in Bazhov's Tales
}

\author{
L.I.Stepanova, D.A.Shchukina \\ Departmentofthe Russian Languageand Literature, Faculty of Humanities and Sciences, Saint \\ Petersburg Mining University, Saint Petersburg, Russia
}

\begin{abstract}
The aimof the articleis to study peculiarities of nominations of minerals in Russian and in its regional version, in the socio-lexicon of the Ural mining workers. For this purpose, a methodological procedure was developed based on the methods of corpus linguistics and an exemplary analysis of the semantic field mineral (minerals) in Russian was performed. The theoretical and methodological procedure is based on the semantic field theory, theory of divergence andthelexical approachproposed by Kevechs. As the material of the study were used the tales (skazy) of Pavel Bazhov .The tales (narrations) of Bazhov are a bright representation of the Ural folklore, regional perception of natural objects, their metaphorical reinterpretation, enrichment of semantic fields associated with the occupation of the inhabitants of the region, with additional semantic meanings. The results of the study reflect the presence of significant differences in the semantic structure of lexemes-nominations of minerals in the Russian language and its regional variant.
\end{abstract}

\section{Introduction}

Language diversity, language variety is one of the most significant scientific socio-cultural problems. Different cultural models, different languages carve up the surrounding world in quite different ways. Previous studies have found significant differences in how languages share the same continuous colour space in different numbers and semantical meanings of basic colour concepts $[1,2,3,4]$, in different spatial descriptions and terms [5,6], in how different languages conceptualize the same spatial relations between two natural objects in cardinal, intrinsic or relative terms $[7,8]$. In the last decades, there has been an increasing number of correlational pieces of evidence that the diversity of the nominations of geographical, natural objects, resources might be motivated by adaptation of society to local natural, social or technological environments [9]

The study of the interactions between language, the environment and the speaker is one of the most actual strands in linguistic sciences. There are many scholarly works aimed at reconsidering "facts about the language structure with facts about speakers and their environmental variables, such as group size, geographic location, genetic composition, and cultural expectations"[10]. At the same time, speaking about such a large and versatile country as Russia, which stretches over 9 time zones, the diversity and differences in its landscapes, we can talk about the formation of additional denotative, connotative or associative meanings of the names of natural objects, natural resources, minerals in the 
regional variants of the Russian language. This study is aimed at exploring the specificity, additional semantic meanings of the names of natural resources, minerals of the Urals. The region is one of the richest in resources and minerals in Russia. For centuries the professional activities of its habitants were connected with mining and processing of precious and semi-precious stones and metals.Due to the specifics of the regional historical development of the names, concepts of minerals acquire particular importance for people inhabiting the Urals, which led to the formation of additional, unique meaning, not present in other languages, cultures, and other regional variants of Russian.

These additional semantic meanings find their representation in regional mentality, the system of regional beliefs, folklore, and individual-authors' discourses. As one of the brightest means of representation of regional perception and interpretation of names of minerals, natural resources the famous Bazhov'sskazymay serve. Skazy is a unique and distinctivephenomenon in Russian literature, originating at the intersection of the global, national, and regional, at the intersection of mythology, folklore, and literature, at the intersection of collective and individual worldviews. Bazhov, according to Litovskaya, is "a creator of the Ural regional identity"[11]. The author's skazy reflect additional regional semantic meanings in the structure of concepts of minerals, may serve as rich material for the study of the specifics of regional perception and interpretation of natural resources. The main purpose of this study is to investigate the usage of nominations of natural resources, natural objects, minerals in the Bazhov'sskazy, to identify additional regional denotative, connotative meanings, mechanisms, and specifics of enhancement or reduction of their semantic fields under the influence of regional factors.

Traditionally investigations of place names and landscape terms can be divided into two main strands: (1) issues related to the investigation of language and conceptualization in national languages and cultural models, study of names of geographical objects for understanding how members of different language communities conceptualize and categorize their environment, revealing universal qualities of human cognition $[12,6,13$, 14]; (2) questions in the investigation of interaction of language and cognition, revealing mechanisms of environmental conceptualization and categorization, the influence of natural resources on linguistic diversity, complexity, the structure of language $[15,16,17 ; 18]$. Critical questions in the second approach to the study are how the names of natural objects, minerals are connected to language? How are they semantically constructed? How regional factors may influence on enhancement/ reduction of the semantic field of nomination? Is the reference to minerals distinguished from references to other objects, other things (people, animals, objects)? In order to answer these questions, a method for investigation of the semantic field of the word mineraly('minerals') in the Bazhov'sskazy is performed.

\section{Review of literature}

\subsection{Semantic field and semantic changes}

Semantic field theory is traced back to the middle of the nineteenth century and the ideas of Humboldt (1836) and Saussure (1916) [19].

The theory is based on the understanding of the field as a system of interactions of different lexemes: "a word [i.e. lexeme] in any language is not an isolated carrier of meaning; on the contrary, each word has a meaning only because there are other words adjacent to it (quoted by 19).

One of the first definitions of the semantic field as a result of interactions, relations of different lexical units, was given by Lehrer (1974), who defines an SF as "a group of words [i.e. lexemes] closely related in meaning, often subsumed under a general term". 
Carpenter [20] defines the SF as "groups of lexical items that share a particular meaning". The definition emphasizes interactions of lexical units and forming of a particular meaning as the result of these interactions.

Scientists define the following types of semantic interactions between lexical units forming an SF [19,20].

1. Hyponymy: subordinate relations in which one lexeme may be defined as the 'headword' [21], superordinate lexeme (or superordinate) [22]. Hyponymy may be multileveled, which means the basic lexical units could be divided into more specific levels. Hyponymy is relative.

2. Synonymy: relations based on the 'ameness of meaning': lexical items may be considered/defined as synonymous if the lexeme L1 implies the lexeme L2.

1. Incompatibility: relations reversive to hyponymy, based on exclusion rather than inclusion: "the sense of one lexeme excludes the sense of other lexemes associated with it in a particular semantic field" [19].

2. Antonymy: relations based on the 'oppositeness of meaning'.

All aspects of language, each specific lexeme, the relationship between them, and, as a consequence, the SFs are constantly changing. Semantic change may be defined as "a habitual modification, among arelatively large number of speakers, in the traditional semantic range of a word thatresults from the use of the word (1) to denote one or more referents it did not previously denote, or (2) to express a new way of apprehending one of its referents" $[23,24]$. In this case,the semantic change leads to the widening of the semantic structure ofthe lexeme. Loss of vocabulary items, denotations can also be defined as a sematic change $[25,24]$, which leads to a narrowing of the semantic structure.

Semantic changes, as a rule, are a result of the influence of linguistic and extralinguistic factors, including geographical, ecological, and biological ones.

\subsection{Influence of natural factors on language structure}

Environmental, geographical objects provide an interesting domain of human labeling, categorization, conceptualization for several reasons [18].

1. First of all, every human being, every community inhabits a landscape, even if its nature is highly changeable and impermanent. Due to settlement, people divide a continuous surface into different parts and segments, the individual fragments that become the object of study, acquire certain inner sense for the individual and society. As Burenhult\&Levinson note [18], "the environment has a profound influence on how we live."

2. The environment andthe landscape provide the fundamental 'Immobilien' (immobility and scale of natural objects) of our worlds. The surroundinglandscape presents itself to the developing child and serves as a backdrop for cognition, for action: "one conceives of the self as necessarily inside it, with the attendant puzzles of wayfinding and navigation" $[26,27,18]$.

In the last decades, the search for relationships between diversity of natural resources and linguistic diversity has often focused on large-scale connections between environmental, cultural, and linguistic diversity. It is generally assumed that environmental diversity directly correlates with cultural and linguistic diversity [28] Supporters of this approach proceed from the understanding that linguistic diversity is a result of a process of linguistic divergence, in which a single linguistic is divided over time in different contexts into more or less independent units. Similarly, the linguistic divergence may lead not to the formation of distinct units, but the splitting of the semantical structure of the lexeme and formation of different regionally marked denotative and connotative meanings in the frames of the lexical item. 
There are numerous studies that have found the effects of environmental variables on linguistic diversity. Collard I. F. \& Foley R. A. [29] have found a positive correlation between temperature and rainfall patterns and cultural and linguistic diversity; Sutherland [30] has found a positive correlation between landscape and language diversity. According to Everett [31], geographical location, the context has a direct correlation with phonological forms of language. So, "there is thus abundant evidence of the effect of environmental variables on language diversity, though a consensus on which mechanisms dominate the build-up of language diversity at the local scale has not been achieved". Thus, we can conclude that environmental, geographical, and natural factors influence language diversity as well as dialectical variants of the same language, and semantic changes of the SF.

Linguistic divergence, language variety may be defined as a process of "inter-group boundary formation [32; 33], referring to the linguistic differentiation of human communities due to constrained communication between them. As factors, restricting communication between social groups generally may be named geographical and environmental barriers (oceans, mountains, dense forests, swamps, etc.) [34, 35]. The influence of environmental, biological, and natural factors is further shaped by cultural, human-related factors. Speaking about the Urals, we can say that the region's geography, nature, environmental characteristics are significantly different from other regions of the country. The specifics of the region, its mineral richness formed the specifics of regional industrial activities related to the processing of natural resources and minerals. So, we can say about influence of environmental and human-related factors on dialect specifics of the Russian language in the region. The influence of regional natural and human-related factors leads to the formation of new denotative, connotative meanings in the semantic frames of Russian lexical units.

The dependence of linguistic diversity on environmental, biological, natural diversity is tightly connected with theory of population divergence within the framework of microevolution [36, 37].

However, not all scientists find equally strong correlations between environmental, biological, and natural factors and language diversity: Moore state that "the form of the relationships between species richness and language richness and environmental factors differs, and it is unlikely that comparable mechanisms underpin the similar patterns of species and language richness". Auer [38] in his study stresses that there are no relationships between geographical location, natural resources, and language variation. Mendívil-Giró [39] underlines that "then the claim that the structure of languages can be explained as the result of an adaptation to environmental factors (social, physical, or otherwise) is misleading and inadequately simplifying".

A skeptical view on correlation between natural, environmental diversity and linguistic diversity is based on two main statements [39]:

1. The influence of the physical, natural environment on language diversity has limited scope for explaining the structure of languages.

2. Such explanations don't lead to a satisfying explanation of what a human language is, from a biological and cognitive perspective, but rather, they take us back to a traditional and incomplete view of language as a purely cultural phenomenon.

As we can see, there is no universal approach to understanding the influence of environment and natural factors and regional specifics on language structures, in the formation of additional meanings andsemantic changes.

In the light of the above arguments, the article focuses on identifying shifts in the semantic field of the word mineral, exploring possible regionally-marked meanings.

The research questions addressed in this article are: (1) Are there any changes in the SF of the word mineralyin the regional Ural variant of Russian? (2) Are there any changes in relationships between structural components of the SF in Russian and its regional variant? 
If so, does location, geographical objects, natural resources have any influence on these semantic changes?

\section{Methodology and materials}

The study of the semantic fieldmineraly ('minerals') in Russian is carried out in the corpusbased analysis of "real and fantastic simultaneously" of Bazhov'sprose[40].

\subsection{Corpus choice}

To achieve of the formulated purpose of the study we need a corpus that demonstrates the usage of the word mineralyin Russian. The corpus citations are taken from the Russian National Corpus, the largest corpus of Russian [41]. The Russian National Corpus "is an information and reference system of a large-scale collection of texts formed in a certain way from the middle of the 18 th century to the beginning of the 21 st century in electronic form, reflecting the Russian language at certain stages of its historical development, in all the variety of genres and styles" [42].So, the Corpus is fitted to the research tasks. For the study, we need a choice of genre and type.

\subsection{Search process}

The search procedure includes the following stages:

1. Searching by lexeme in all forms.

2. Limiting the search by the part of speech of the same lexical item.

3. Choosing a particular sub-corpora (Bazhov discourse) according to genre (fiction) and type (skazy).

4. Grouping results by words.

5. Ranking the results: ranking is understood as a procedure, which provides "ordering any objects based on preferences for a selected feature"[43].

\subsection{Qualitative analysis}

To achieve this goal,Kövecses's lexical approach was chosen as a qualitative research method. The research process includes the following stages:

1. Revealing the denotative meaning, fixed in dictionaries: a generalization of dictionary definitions, description of lexicographic meaning. The method is aimed at obtaining the most complete description of the meanings based onthe analysis of available dictionary studies $[44,45,46,47]$.

2. The etymology of the lexeme.

3. Relations to other lexical items of the SF (synonyms, antonyms, hyponyms, incompatible lexemes).

\section{Results}

\subsection{The lexeme mineraly ('minerals')}

\subsubsection{Searching by lexeme in all forms}


Table 1. Frequency of lexeme mineraly ('minerals').

\begin{tabular}{lllll}
\hline Lexeme & $\begin{array}{l}\text { Frequency in } \\
\text { corpora }\end{array}$ & $\begin{array}{l}\text { Frequency in } \\
\text { fiction }\end{array}$ & $\begin{array}{l}\text { Frequency } \\
\text { inskazy }\end{array}$ & $\begin{array}{l}\text { Frequency in } \\
\text { sub-corpora }\end{array}$ \\
\hline $\begin{array}{l}\text { mineraly (minerals) } \\
\text { mineralov(of minerals) }\end{array}$ & 595 & 63 & 1 & 0 \\
$\begin{array}{l}\text { mineralam(for/ to } \\
\text { minerals) }\end{array}$ & 50 & 71 & 2 & 0 \\
$\begin{array}{l}\text { mineralami(by/ with } \\
\text { minerals) }\end{array}$ & 177 & 22 & 0 & 0 \\
$\begin{array}{l}\text { mineralakh(about } \\
\text { minerals) }\end{array}$ & 137 & 5 & 0 & 0 \\
\hline
\end{tabular}

The results of the quantitative analysis reflect that the lexical unit is widely used in Russian (2197 items) in fiction the word is used 163 times, but in skazythe item is used only 3 times. Bazhov does not use the nomination.

Examples of the of the lexeme are as follows:

Pod nazvaniyemasbestob'yedinenymineralyizklassamagniyevykhgidrosilikatov(Minerals from the class of hydrous magnesium silicates are combined under the name asbestos )corpora (1).

On schitalikhtakimzhedaromzemli, kakimineraly, temboleyekarel'skayazemlyabylastol' bogataitem, idrugim(He considered them the same gift of the earth as minerals, all the more so that the Karelian land was so rich in both)_ fiction(2).

Lomonosov deystvitel'noshumel: yeshchebatyushka Petr Alekseyevichprikazyvalposlat'v Sibir' po mineraly... (Lomonosov was really roaring: As far back as tsar PyotrAlekseevich ordered to send for minerals to Siberia...) - $\operatorname{skazy(3).}$

In all examples, the lexeme is used in its denotative meaning for the nomination of natural elements obtained from the ground. In the fiction, the meaning gets connotations of natural richness (darzemli). The place of origination of minerals in skazy is Siberia, a region tightly connected with the Urals. We can conclude that in the national mentality minerals are deposits of natural elements, natural wealth obtained in Siberia and the Urals.

\subsubsection{Denotative meanings.}

In dictionaries denotative meaning of the word mineraly ('minerals') is represented in the following ways:

1. A natural chemical compound, an inorganic body, solid or liquid, a part of the earth's shell; often serves as an object of extraction and processing, as a mineral[48].

2. Anatural inorganic formation of a crystalline structure, approximately homogeneous in chemical composition and physical properties, lying in the depths or on the surface of the earth and usually serving as a subject of extraction as a mineral) [49].

3. A physically and chemically individualized body forming as a result of natural physicochemical processes in the Earth's crust[50].

The conducted approaches allow us to define the mineral as a natural solid homogeneous crystalline chemical and physical element that results from the inorganic processes of nature, usually obtained from the ground and serving as an object of processing.

The lexeme has a singular denotative meaning, but every definition emphasizes on different meaningful aspects of the item: the first one - on the natural character of its formation; the second one - on its origin from the ground; the third one - on its homogeneous structure. 


\subsubsection{The etymology of the lexeme}

In dictionaries since 1771 we see mineral. :From German 'Mineral', rising to late Latin 'miner' — “ore", mineralis and further to * mīna, i.e.mine, ore vein [51].

In Russian, the lexeme was fixed in the 18th century, the word was borrowed from German. The original meaning remains in modern Russian.

\subsubsection{Relations to other lexical items}

\section{Synonyms}

Analysis of sub-corpora and dictionaries hasn't revealed lexical units with similar meaning [52, 53, 54].

Antonyms, incompatibility

Analysis of sub-corpora and dictionaries hasn't revealed lexical units with an opposite meaning $[52 ; 55,54]$ or lexical items based on the necessity of exception of the lexeme.

Hyponymy

The lexeme mineraly is a hyperonym for all other lexemes of the SF. The lexeme integrates 5627 lexical units in the SF [56]. At the same time, the lexical unit doesn't fit other criteria of basic lexemes [21]: (1) it doesn't actively participate in the formation of new concepts, nominations of real and fiction objects; (2) it is restricted to a narrow class of objects; (3) it isn't psychologically 'salient' for informants. So, for more than 200 years of functioning in Russian, the word hasn't become a culturally-marked unit.

Separate components of the SF freely interact with other lexical items, form synonymous, antonymous, etc. relationships with other words of the SF. As the lexemes with the greatest number of relations with other lexical units in the dictionary are presented the followings (ASIS Dictionary of Synonyms2013): (1) gold $(36)^{* 1}$, (2) titanium (27), (3) silicate (24), (4) chalcedony (20), (5) silver (20), (6) spinel (19), (7) iron (18), (8) granite (17), (9) flint (17), (10) marble (15).

Frequency of the hyponyms in corpora, fiction, skazy and Bazhov discoursemay be presented in the Table 2:

Table 2. Frequency of lexemes of SF mineraly

\begin{tabular}{lllll}
\hline Lexeme & $\begin{array}{l}\text { Frequency in } \\
\text { corpora }\end{array}$ & $\begin{array}{l}\text { Frequency in } \\
\text { fiction }\end{array}$ & $\begin{array}{l}\text { Frequency } \\
\text { in skazy }\end{array}$ & $\begin{array}{l}\text { Frequency in } \\
\text { sub-corpora }\end{array}$ \\
\hline gold & 15567 & 12661 & 130 & 59 \\
titanium & 1104 & 233 & 0 & 0 \\
silicate & 57 & 2 & 0 & 0 \\
chalcedony & 40 & 17 & 0 & 0 \\
silver & 10521 & 4497 & 9 & 4 \\
spinel & 42 & 5 & 0 & 0 \\
iron & 12238 & 5566 & 30 & 28 \\
granite & 1988 & 813 & 0 & 0 \\
flint & 730 & 464 & 2 & 2 \\
marble & 3291 & 1668 & 3 & 3 \\
\hline
\end{tabular}

As the conducted results reflect, most frequentlyoccurring nominations ofminerals in corpus, in fiction, in the skazy and in Bazhov discourse are: (1) gold, (2) iron, (3) silver, (4) marble. The frequency of usage of other lexemes differs. Based onthe ranking, nominations of minerals may be presented in Figure 1:

" numberofrelationshipsofalexeme 


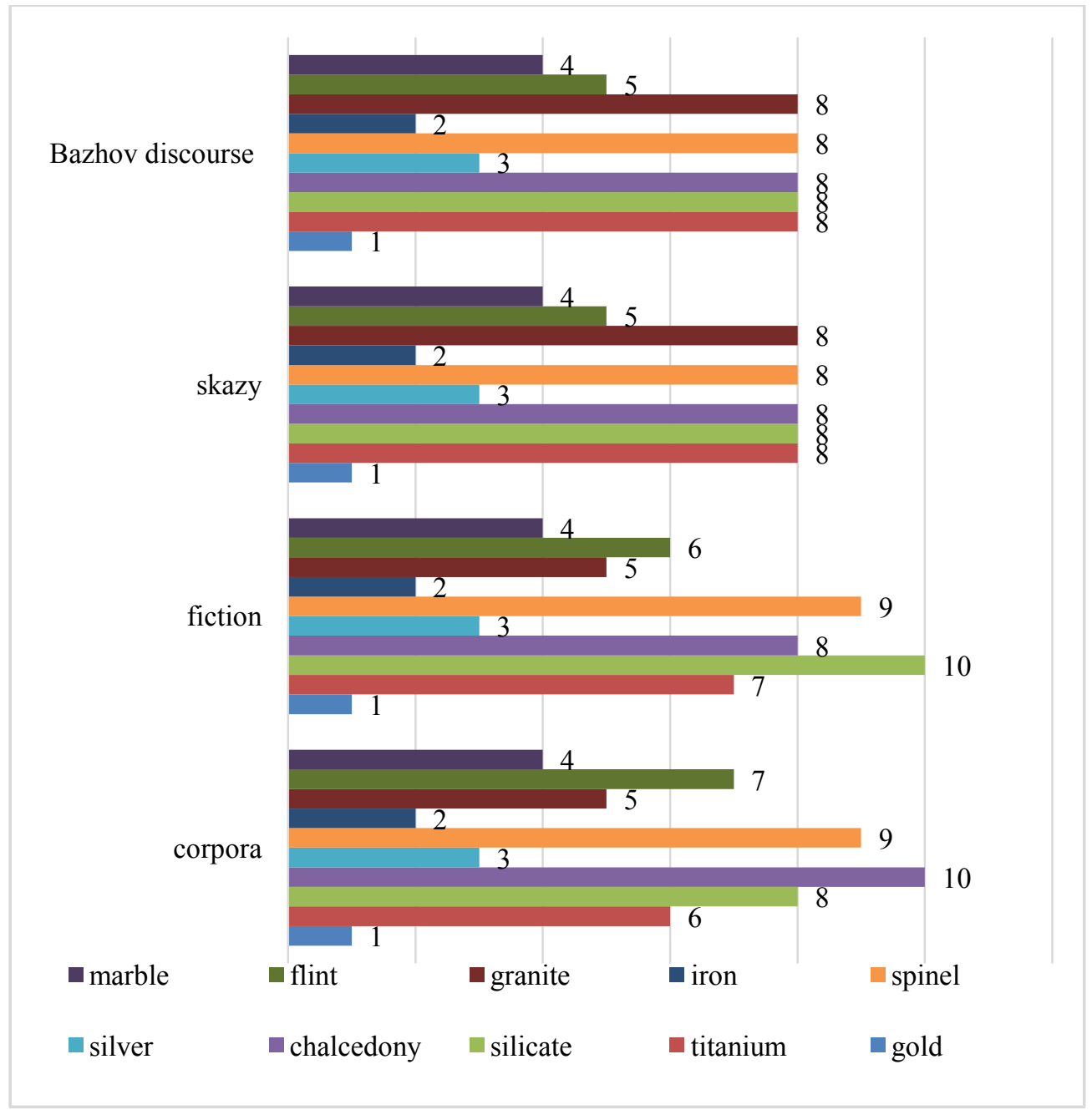

Fig. 1. Results of ranking the lexemes-nominations of minerals.

Comparison of the results of the ranking of lexeme-nominations of minerals in corpora and fiction reflects that in fiction the frequency of the lexemekremen' ('flint') is higher than in corpora, that allows suggesting that qualities of this mineral more fitted to the aims of fiction.

There are no differences in the frequency of the use of lexemes-nominations of minerals in theskazy and Bazhov discourse are absent. There are no differences in the frequency of the use of lexeme-nominations of minerals in the fable and Bazhov discourse. Differ from corpora and fiction terms silikat ('silicate'), titan ('titanium'), khaltsedon ('chalcedony'), shpinel' ('spinel'), granit ('granite') are absent in Bazhov discourse. Moreover, if in corpora and fiction the lexeme 'granite' places $5^{\text {th }}$ position in ranking, in skazy this position is replaced by the word 'flint', that allows to suggest that for theskazy the qualities, connotative meanings of the last lexical item are more important.

It is worth emphasizingthe percentage comparison of frequency of lexemes-nominations of minerals in the skazy and Bazhov discourse (Figure 2): 


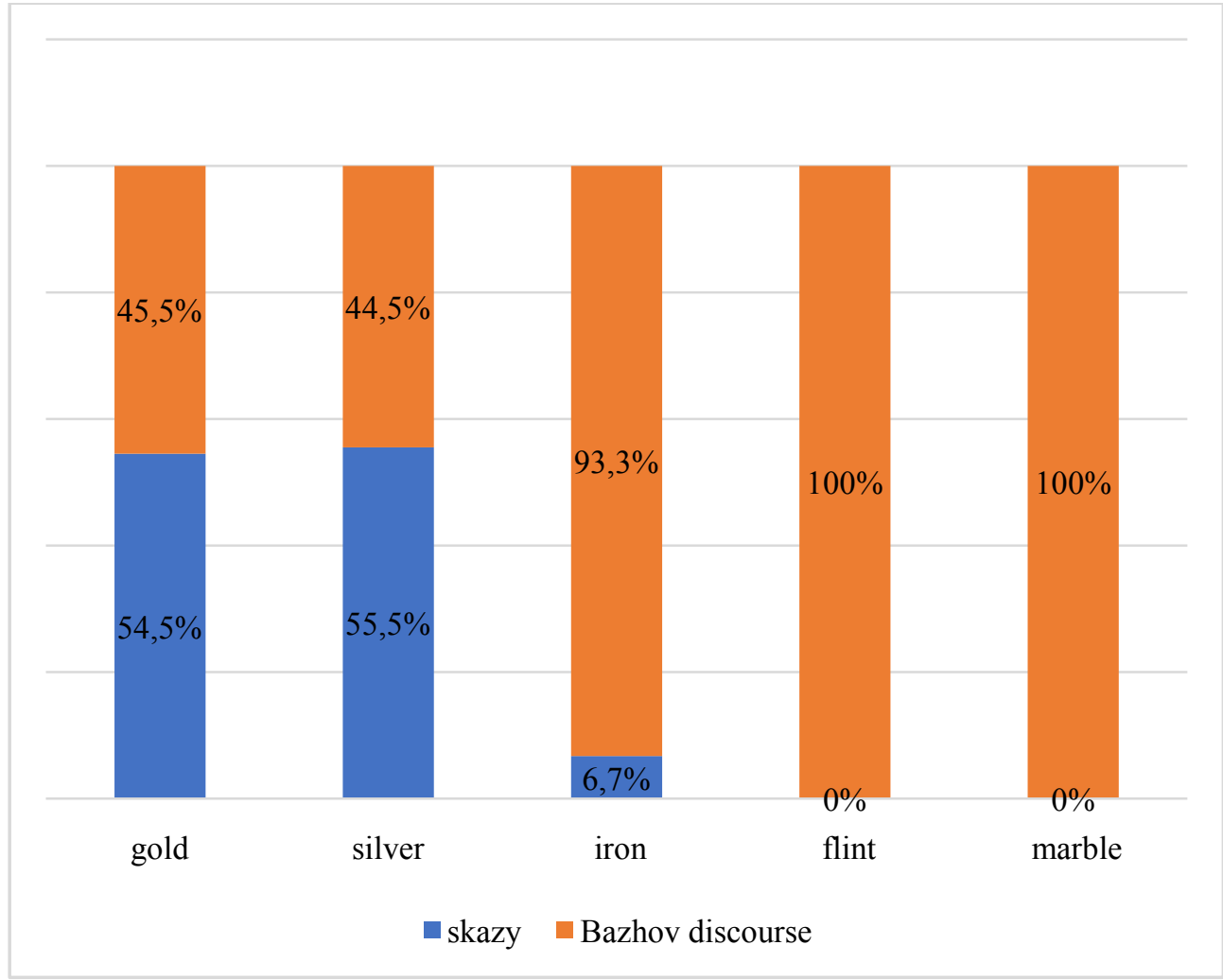

Fig. 2. Percentage comparison of frequency of lexemes-nominations of minerals in the skazy and Bazhov discourse.

As we can see, functioning of the lexemes-nominations of minerals in the skazyis connected withBazhov discourse: such lexemes as mramor('marble'), kremen'('flint') were conducted into theskazy by the author, they don't used outside of his works. The number of cases of the use of the lexeme zhelezo('iron') outside Bazhov discourseis limited to $6,7 \%$ of the total. The lexical items zoloto('gold'), serebro('silver') are more frequent in skazy, but as well the share of the use of the nominationsserebro('silver') in Bazhov discourse is $44,5 \%$ of the total, «золото» ('gold') - 45,5\%.

So, the results of quantitative analysis allow us to make conclusion, that the lexemesnominations of minerals in the skazy are tightly connected with Bazhov discourse.

\subsubsection{The lexeme of gold}

\section{Denotative meanings}

In dictionaries denotative meanings of the word zoloto('gold') are as follows[51,48]:

1. One of the noble metals of yellow color, which is used for the manufacture of precious products, a measure of value:

GdetakayaPoskakushkapokazhetsya, tam izoloto. Ne sil'noyezoloto, zatogrudnoye, i ne plastomlezhit, a vrodered'kiposazheno("Where such Poskakushka appears, there is gold. Not strong gold, but in nuggets, and not in a layer, but planted like a radish.")(4).

In this context, the nomination of mineral, first of all, reflects specifics of the Ural deposits ofgold, so-called placer gold [57], as well itserves toachieve the purpose of 
"creation of a living mythological picture in which everything moves according to the rules of myth, but these rules seem to be born together with the action, so we see here the confluence of the mythological and literary" [58].

2. Items made of gold:

Nozhnytakisverkayutzolotom da dorogimikamen'yami.(The scabbard sparkles with gold and precious stones.)(5)

3. Figurative: someone with great dignities.

4. Collective: gold coins.

5. Silk threads covered with a thin layer of gold.

6. Figurative: affectionate appeal.

Gold in Bazhov'sskazy is a yellow metallic element: the $1^{\text {st }}$ and the $2^{\text {nd }}$ denotative meanings. The semantic structure of the lexeme is narrower, than fixed in dictionaries.

The etymology of the lexeme

In Russian,in the 11th -17 th centuries two forms of the word were in use. In Church Slavonic the lexeme has the forms of zolotoand zlato.This dates back to Indo-European* g'hl-: g'hel-: ghel- "yellow, green, gold". Nomination of the metal is based on its color [51].

The lexeme is fixed in Russian in the 11 th -17 th centuries. It was used in Proto-Slavic for the nomination of yellow metallic element: the $1^{\text {st }}$ and $2^{\text {nd }}$ denotative meanings, examples 4,5 .

Relations to other lexical items

Synonyms: in dictionaries, the following synonymous meanings of the lexeme are presented [53].

1. Gold = wealth, high social status:

Ne poydu v goru, khot' zolotomosyp'!(I will not go up the hill, even if it is scattered with gold).(5)

Phraseological unit of Russian ('scatter with gold')has meaning ('enrich (colloquial))'.

2. Amazing= golden, shiny.

Antonyms, incompatibility:analysis of sub-corpora and dictionaries hasn't revealed any lexical units with an opposite meaning (Lvov1984; Dictionary of Synonyms and Antonyms of the Modern Russian Language; Diploma. RU 2020) or lexical items based on the necessity of exception of the lexeme.

The nomination of gold in Bazhov discourse is tightly connected with regional mythology. This raises difficulties in understanding the phrase "stone power," which Bazhov used in the tale Zolotye Daiki ("Dikes of Gold") to describe the condition of an Old Believer artisan miner Yerofei Markov, the discoverer of gold in the Urals. It is stone power that forces him to release the "golden serpent from the Earth" [59]. However, it can be said that this "stone power" also belonged to Bazhov himself, forcing him to write more and more stories about the Ural Mountains, the Stone Belt of Russia.

\subsubsection{The lexeme of iron}

\section{Denotative meanings}

In dictionaries denotative meanings of the word zhelezo('iron') are as follows [51; 48]:

1. The most widespread in nature heavy metal of silvery color, with an admixture of different amounts of carbon forming steel and cast iron:

Vezdebogatstvapolozheno: s zakatnogoboku med', s voskhodnogo zhelezo(Everywhere wealth is laid: copper from the sunset side, iron from the sunrise).(6)

2. Only singular: Iron items, products made of iron:

Takoyznakistavit'-to nazheleze s bol'shoyoglyadkoysleduyet(Such a sign should be put on the iron with great caution).(7)

3. Only singular: Medicinal preparation from glandular substances (medical). 
4. Only plural:irons, shackles (archaic poetic).

Additionally, in the sub-corpora, the following meaning is presented:

Zheleza $\mathrm{v}$ tuporumalodelali, bol'she med' plavili(Not much iron was being made in those days, more copper was being smelted).(8)

The difference from designations recordedinthe dictionary, in this case the lexeme emphasizes the artificial nature of iron, the fact that iron is the result of ore processing. The semantics of concept reflectsa great pragmatic potential of associations and similarities between natural, technical objects and humans[60].The meaning of the concept is based on the $1^{\text {st }}$ denotative meaning, but emphasizes the purity of iron, the absence of impurities. Nomination of a natural object reveals and describes not only the moral system of human values, but also the properties, scientific characteristics of objects [42].

The etymology of the lexeme

The very word zhelezoappeared in the Russianlanguage since the 11th-17th centuries where it came from the Proto-Slavic zhelzo, derived from the nomination of the animal gland, zheleza. The image of a glomerulus, a lump was used for the figurative (and possibly taboo) designation of the marsh iron exactly in the form in which the Proto-Slavs first got to know it. In its appearance, the marsh iron ore looks like dense, reddish earthy lumps. The word zhelezo is a reminder of the ancient cultural stage of mining and processing of the marsh iron ore [51].

The lexical unit is fixed in Russian since the eleventh century, borrowed from the ProtoSlavs. The appearance of the lexeme in the language was caused by appearance of new types of people's activities: mining and processing marsh iron. Etymologically, the lexeme was borrowed to nominate natural objects - the $1^{\text {st }}$ denotative meaning - Example 6 .

Relations to other lexical items

Synonyms [55]:

1. Mineral, element are hyponyms, the key word of the SF:

Pervyy sort, martit! Chut' ne tsel'noyezhelezo. Stalidobyvat' ividyat: zhila ne v tustoronuidet, gdeblizhniyzheleznyyrudnik (First sort, martite! Almost solid iron. They began to mine and see: the vein is going in the wrong direction, away from the nearest iron mine).(9)

2. A car.

3. Metal:

Soldering acid, with which iron is attached to iron, and that, they say, the trays of good skill withstood(Soldering acid, with which iron is attached to iron, andthat, they say, withstood trays of good workmanship).(10)

4. Severity.

Antonyms, incompatibility:analysis of sub-corpora and dictionaries hasn't revealed any lexical units with an opposite meaning [52, 55, 54] or lexical items based on the necessity of exception of the lexeme.

\subsubsection{The lexeme of silver}

\section{Denotative meanings}

Denotative meanings of the word serebro('silver') are as follow[51, 48]:

1. A grayish-white precious soft metal with luster:

Postavil, kak u nasvoditsya, v izbechugunnuyubokovushkukusinskojrabotyistal po zakazumetall $v$ sin' da v serebrorazdelyvat'(He put, as usual, Kusino'scast-iron oven in the hut and began to cut metal into blue and silver by order).(11)

2. Thecolor, luster of this metal.

3. Collective: small coins made of alloy, in which the main constituent is silver or nickel: 
$N u$, a kto ne upiraetsya, - tomustakan vina da rublevkaserebra(Well, and who does not resist, for that a glass of wine and a ruble of silver).(12)

The etymology of the lexeme

The lexeme was fixed in Old Russian in the $11^{\text {th }}$ century, but as scientists underline, it was borrowed from Proto-Slavic. By Proto-Slavic the lexeme was borrowed from Asia Minor(Chernykh 1994), and today exactly date a period of borrowing is impossible. Etymologically the lexeme was borrowed to nominate natural object - the $1^{\text {st }}$ denotative meaning - Example 1.

Relations to other lexical items

Synonyms: (1)gray, (2) hoarfrost [55].

Antonyms, incompatibility:analysis of sub-corpora and dictionaries hasn't revealed any lexical units with an opposite meaning $[52,55,54]$ or lexical items based on the necessity of exception of the lexeme.

\subsubsection{The lexeme of marble}

\section{Denotative meanings}

Denotative meanings of the word mramor('marble') are as follows [52,55]:

1. Only singular:hard limestone, used as a material in sculpture and architecture mainly:

Pol, naprimer, gladkij-pregladkij, izsamogoluchshegomramoru, a posredineklyuch, ivoda, kaksleza (The floor, for example, is the smoothest, made of the best marble, and in the middle is a key, and water is like a tear ).(13)

2. An item made of marble.

3. Used in comparative constructions as a symbol of coldness, dispassion.

Additionally, in sub-corpus the following meaning is represented:

PoslalisejchaszhenaMramor za samymhoroshimkamnerezom(Sent immediately to Marble for the best stone cutter).(14)

Mramorin the context is a toponym, nomination of geographical object, place of deposits and/ or processing of the material. It is worth emphasizing the nomination is colloquial, in regional dictionaries the name isn't fixed, so concretize the place is impossible. The toponym is formed as the result of metaphorical rethinking of specifics of diversity of natural resources specifics of regional industrial activities and its further use as nomination of the settlement.

The etymology of the lexeme

In the Russian language, the lexeme was fixedin the 12th -15 th centuries:marmar, marble. It dates back to Byzantine Greek "shining, sparkling (stone)". It is impossible to exclude the influence of Latin'marmor'onthe Old Slavonic word. The word was borrowed (in historical time) from the Greek. Compare: $\mu \alpha \rho m \alpha i ́ \rho \omega<* \mu \alpha \mu \alpha \rho \omega$ "shine", "sparkle"[51].

The appearance of the lexical item in Russian was connected with Christianization of the country,the influence of Byzantium, and the established tradition of churches' designing, later - palaces' building tradiotion. A contradictory situation arises: on the one hand, the Urals are rich in marble deposits, on the other, - appearance of the lexeme is connected with the ontological cultural changes.

Relations to other lexical items

Synonyms: mineraly(mineral) - hyponym of the SF, stone, calcite [55,53].

As demonstration of the use of the lexeme in themeanings'stone', 'calcite' the Examples 13 may serve.

Antonyms:analysis of dictionaries hasn't revealed any lexical units with an opposite meaning $[52,55]$.

At the same time,Bazhov appeals to the following semantic opposition: 
v kotorommesteumerikakoj emu pamyatnikpostavi-li: to li izital'yanskogomramora, to li izzdeshnegochuguna (in which place he died and what monument was erected to him: either from Italian marble, or from local cast iron).(15)

Italian marble in the fragment serves as an opposition to local cast iron. The formation of the opposite semantic meanings may be explained by specifics of historical development of Russian architecture. As it was mentioned early, the appearance of the lexeme 'marble' was connected with Christianity and the necessity of erection of churches. But the main period of flourishing of Russian marble art is the period ofof St. Petersburg's building. In that time, the usage of marble for the building was connected with names of Italian masters. So, we can see, that in the author's discourse marble is perceived as 'foreign, not zdeshnij', differ from cast iron. The opposition of the semantic meanings is based on (1) the opposition of the location of deposits: Italian - local; (2) the functional opposition: marble is material of erection of churches, beautiful, monumental, but unpractical buildings, cast iron - material for the manufacture of household items, characterized by practicality and functionality.

Incompatibility:analysis of sub-corpora and dictionaries hasn't revealed lexical items based on the necessity of exception of the lexeme[52,55, 51].

\subsubsection{The lexeme of flint}

\section{Denotative meanings}

In dictionaries denotative meanings of the word kremen'('flint') are as follows[51,48]:

1. A very hard stone, previously used to strike fire:

EtotVlasychpridumalsvarit' takuyustal', chtobsrazutrutbrala, eslitojstal'yuryadom po kremnyucherknut'(Vlasych came up to the idea to weld such steel that it would immediately take tinder, if you drop a line by that steel to the flint).(16)

2. Fgurative:About a man with a persistent, unyielding character, a miser:

Skazala, kakotrezala. Kremen'-devka(She said as she. Flint-girl). (17)

The etymology of the lexeme

In Russian,since the 11th - 17th centuries where it was borrowed from the ProtoSlavickremy, kremene, from the preform* ak'-men_— "smth. sharp". The Proto-Slavic * kremy, * kremenemaydate back to the Pre-Slavic * krek-mon-, * krek-men- "smth. for striking of fire". [51].

Etymologically the lexeme was borrowed to nominate natural objects - the $1^{\text {st }}$ denotative meaning - Example 16.

\section{Relations to other lexical items}

Synonyms: (1) mineral -hyponym of SF,' 'stone', (2)cool, harsh, tough, persistent [55,53].

As demonstration of the use of the lexeme in themeaningsmineral, kamen' ('mineral, stone') the Example 16 may serve. As demonstration of the use the lexeme in the meanings «krutoj, surovyi, zhestkij, stoikij» ('cool, harsh, tough, persistent') the Example 17 may serve.

Antonyms, incompatibility:analysis of sub-corpora and dictionaries hasn't revealed any lexical units with an opposite meaning [52,55,53] or lexical items based on the necessity of exception of the lexeme. 


\section{Discussion}

As the results of the study reflect the lexeme mineraly('minerals') is used in corpora, fiction, the usage of the item in the skazy is limited. Analysis of the functioning of the word allows us to conclude that the lexical unit is associated in consciousness of speakers with natural wealth and the Urals.

The lexeme has one denotative meaning, nominate all chemical and physical elements obtained from the ground and served as an object of processing, manufacturing.

The word appeared in Russian in 18th century.It was borrowed from German as a term. Since 18th century it hasn't become a culturally-marked unitin Russian.

The item is a collective nomination for 5627 nominations of different minerals. Nominationsof minerals participate in establishing of relationships with other lexemescomponents of the SF mineraly('minerals'). As the lexemes with the greatest number of relations with other lexical units in dictionaries are presented the followings: (1) gold, (2) titanium, (3) silicate, (4) chalcedony, (5) silver, (6) spinel, (7) iron, (8) granite, (9) flint, (10) marble. The frequency and meaning of the lexemes-nominations of minerals in Russian and its regional variant significantly differs. The most frequent nominations of minerals in corpus, in fiction, in the skazy and in Bazhov's style are: (1) gold, (2) iron, (3) silver, (4) marble. At the same time, such lexemes as titanium, silicate, chalcedony, spinel, granite in Bazhov'sskazy are absent. Moreover, granite places the $5^{\text {th }}$ position in corpora ranking, in Bazhov'sskazy this position is taken by the word flint. As the results of the analysis demonstrate, the denotative meanings of the flinthas actualized in the regional narration.

Comparative analysis of the semantic structure of the SF mineraly('minerals') in Russian and its regional variant may be presented in the Table3:

Table3. Comparative analysis of the structure of the SF mineraly('minerals')in Russian and its regional variant

\begin{tabular}{|c|c|c|}
\hline & Russian & Regional variant \\
\hline \multicolumn{3}{|l|}{ Gold } \\
\hline \multirow[t]{6}{*}{ Denotative meanings } & \multicolumn{2}{|c|}{$\begin{array}{l}\text { One of the noble metals of yellow color, which is used for the } \\
\text { manufacture of precious products, a measure of value }\end{array}$} \\
\hline & Items made of gold & \\
\hline & $\begin{array}{l}\text { Figurative: someone with great } \\
\text { dignities. }\end{array}$ & \\
\hline & Collective: gold coins & - \\
\hline & $\begin{array}{l}\text { Silk threads covered with a thin } \\
\text { layer of gold }\end{array}$ & - \\
\hline & Figurative: affectionate appeal & - \\
\hline $\begin{array}{l}\text { The etymology of the } \\
\text { lexeme }\end{array}$ & \multicolumn{2}{|c|}{$\begin{array}{c}\text { Since the } 11 \text { th century from Proto-Slavic: the } 1^{\text {st }} \text { and the } 2^{\text {nd }} \text { denotative } \\
\text { meanings. }\end{array}$} \\
\hline Synonyms & \multicolumn{2}{|l|}{ Gold $=$ wealth, high social status } \\
\hline & \multicolumn{2}{|l|}{ Amazing $=$ golden, shiny } \\
\hline $\begin{array}{l}\text { Antonyms, } \\
\text { incompatibility }\end{array}$ & \multicolumn{2}{|c|}{ - } \\
\hline \multicolumn{3}{|l|}{ Iron } \\
\hline Denotative meanings & \multicolumn{2}{|c|}{$\begin{array}{l}\text { The most widespread in nature heavy metal of silvery color, with an } \\
\text { admixture of different amounts of carbon forming steel and cast iron } \\
\text { Only singular: Iron items, products made of iron }\end{array}$} \\
\hline
\end{tabular}




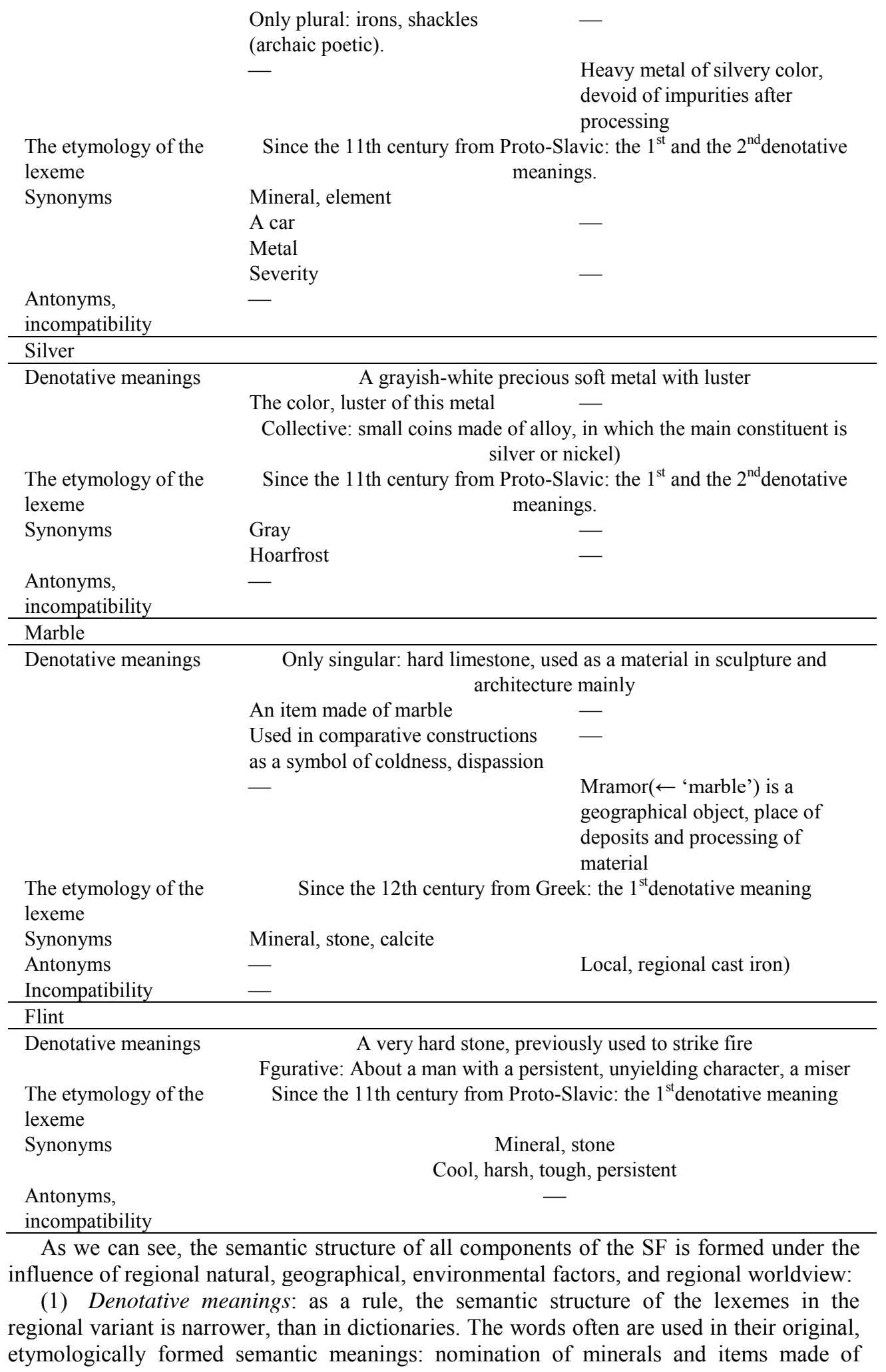


minerals. In this case we can see contradictory situation: as a rule, biological, environmental diversity is considered as a basis of language diversity. But, as we can see, natural wealth, mineral diversity of the Urals doesn't lead to enhancement of the semantic structure of the lexemes-nominations of minerals, theformation of additional denotative, and connotative meanings. The lexemes loss their figurative meanings: gold —affectionate appeal, iron -irons, shackles, marble - a symbol of coldness, dispassion. For the habitants of the Urals mineral is a deposit, material, they must find, mine and process.Minerals are basis of regional industry. So, the regional variant emphases on functional features, functional characteristics of minerals. Here, there is another important hero that should not go unspoken about. It is the "master", who is considered to be a professional in any craft, so, in his opinion, one cannot do without an ethical, moral criterion (the tale "The Mountain Craftsman"),especially if ... a model is created, an ideal" [61].

Stones and metals in the works of P.P. Bazhov fulfill not only artistic functions, but also become "the basis of the life and existence of the Ural worker, who since childhood has perceived astone as afabricating material, wonderfully transformed in the skillful hands of a person with a delicate taste and rich imagination" [62]. Therefore, the writer depicts stones and metals from both sides: practical as well aesthetic value.

However, regional perception of geographical specifics, mineral, natural factors leads not to reduction of the semantic fieldonly, but as well to forming of new denotative and connotative meanings, for example: Mramor is a geographical object, place of deposits and processing of marble. In this case the place of mineral deposits became the basis of nomination of the geographical object.

(2) The etymology of the lexemes:the results of study reflect that the lexemesnominations of minerals appeared in Russian in ancient times, were borrowedfrom Old Russian and Proto-Slavic. The appearance of the lexemes was caused by appearance of new types of occupationconnected with minerals' processing. The etymological analysis of the lexeme brightly reflects the high degree of dependence of ancient communities from biological, natural resources. The exceptions are lexemes silver and marble. The first one was borrowed from Asia Minor in ancient times to nominate metal. The borrowing of the second lexeme was connected with Christianization of Russia, and ontological cultural factors. The etymological meaning of the lexeme has negative estimations, associations of the mineral in Bazhov discourse.

(3) Synonyms: as a rule, there are no additional synonymous meanings in theskazy. The tendency to narrowing of the semantic structure of the lexemes may be explained by specifics of industrial life of the region and dependence of its habitants on processing of minerals.

(4) Antonyms: the results of study reflect that, as a rule, there are no additional antonymous meanings to the lexemes-nominations of minerals. At the same time, we may define regionally marked antonym: Italian marble — local, regional cast iron.

So, we can conclude that the SF of the lexememineraly('minerals') in Bazhov discourse, in the region significantly differs from fixed in dictionaries, regional biological, geographical, environmental factors influence on the enhancement/ reduction of the semantic structure of components of the SF. Nominations of minerals serve to achieve the purpose of reflection of geographical, natural specifics of the Urals, but as well are able to "describe the most difficult problem situations of a modern person" [63].

Among other significant lexical items in the SF mineraly('minerals') in Bazhov discourse it is worth to note malachite - "a bright green mineral stone has black veinlets, and is used for various crafts" [64]. Indeed, the miraculous box that was gifted by the Mistress of the Copper Mountain was made of malachite. 
As a rule, the lexeme is used as a nomination of mineral, ornamental stone, to reflect the peculiarities of the life of the inhabitants of the region. However, under the influence of the individual author's worldview, the noun can acquire the additional connotations, in particular, it becomes a symbol of wealth and high social status of its owner:

Da imalahit-to podelochnyj, samogovysokogosortu(And malachite is ornamental, of the highest grade).(18)

In this case, we are talking about an ornamental stone, a stone of the "highest grade", the lexeme participates in the formation of the terminological unit of the mining industry for nomination of the material that suitable for processing and manufacturing luxury items.

As another example of semantic changes in the regional variant of language may serve the following:

Poplakala, glyadit - u samojnogimalahit-kamen' oboznachilsya, tol'koves' $v$ zemlesidit(She cried, she looked - the malachite-stone has appeared at the very foot. But it whole sits in the ground). (19)

The semantic structure of the lexeme already contains the meaning of a stone (malachite is a stone), respectively, in the example the new composite is based on a semantic tautology (stone - stone). The lexeme is an author's neologism, the result of an individual author's linguistic creative work aimed at reflecting the dialectal features of the Ural dialects. As the result the narration acquires the character of a "live" sounding speech, expressiveness and imagery. It is important to add, that the malachite-stone in Bazhov's work is presented as a living creature "sitting in the ground". Such understanding of the stone is the result of a metaphorical rethinking of the realities of the socio-natural environment.

Copper is "widely used in the industry" [64], that is why the mountain is named after this metal. At the beginning of the tale "The Mistress of the Copper Mountain", there is an indication of the extraction of various minerals: "Malachite - ore were mined" [59].

The word "orlets" - "the old Russian name of rhodonite", a mineral of "pink color, which is used as an ornamental stone"[64]- is presented in the tale "A Fragile Twig": "For roots and leaves, there was also a certain order: some of the orlets and from some other stone" [59]. In the same tale, agate is being mentioned, "a solid mineral consisting of layers of various colors" [64]. Jasper is a nontransparent ornamental stone of variegated coloration, often having veinlets of red, gray or green" [64].

In the tale "Silver Hoof", chrysolite is mentioned, the name of which in Greek means "golden stone", but in Russian language this word is used to describe "a green color mineral with a golden hue"[64].

Thus, we observe the practical role of stone in the life of fairy tale heroes, considering the fact that stone is a common natural material that is actively mined in the Urals and constitutes an important part of the region's economy.

It is interesting to note that the reader may find widely known minerals that are used in the production: copper ("The Mistress of the Copper Mountain"), tin ("A Fragile Twig"), asbestos ("The Silk Hill").

As the result of the study of linguistic material, we come to the following conclusions. Images of stone and metals in the works of P.P. Bazhov are presented, first of all, in practical implementation as the backbone material of works of art created by "skilful fingers" and the talent of masters. The stone turns out to be closely related to the problem of aesthetic perception of both works of art and stone jewelry.

The stone in Bazhov's tales is the main symbol and at the same time the everyday reality of the Urals, which is known to be a stone kingdom compared to the Central Russia. The ideal embodiment of the stone kingdom is the mountains, representing the spiritual center of the world as a symbol of excellence, eternity, purity, eternity, ascent, aspiration and challenge. It is no coincidence that in the overwhelming majority of Bazhov's tales, particularly mountains are depicted as the ideal scene. 


\section{Conclusions}

Study of names of geographical objects, minerals, landscape terms becomes one of the most important directions of linguistic sciences. Language diversity, regional variants of language demands on cultural, social, and natural, environmental,biological factors. The article was devoted to study of the SF mineraly in Bazhov'sskazy.

The results of the study reflect that the SF is associated in the consciousness of the Russians with the Urals, its natural, mineral wealth and diversity. The term is used for nomination of all metals and stones, all resources obtained from the ground and serves as an object of processing. There are 5627 nominations of different materials in structure of the SF.

Comparative analysis of the structural components of the SF reflects the significant differences in perception and functioning of the lexemes-nominations of minerals in Russian and its regional variant. First of all, we must stress on reducing of the semantic structure of the lexemes in the Bazhov'sskazy. For the author and the habitants of the Urals minerals are basis of practical occupation, industry, that leads to loosing of figurative denotative and connotative meanings. However, loosing of some meanings is accomplished by formation of new regionally and often professionally marked ones.

We must note, that there is no direct correlation between environmental,biological, mineral diversity and linguistic diversity. The regional mineral diversity doesn't lead to increasing of additional meanings in the semantic structure of nominations of minerals. But we can constant the fact of the influence of environmental, biological factors on the semantics of the lexemes. The sematic structure may become more complex, may be enhanced, or simpler, may be reduced.

The reported study was funded by RFBR, project number 20-31-70001.

\section{References}

1. B. Berlin, P. Kay Basic color terms: their university and evolution. California University Press, (1969)

2. D. T. Lindsey, A. M. Brown Color Naming and the Phototoxic Effects of Sunlight on the Eye. Psychological Science,13(6), 506-512 (2002)

3. D. Plewczynski et al. Generic Framework for Simulation of Cognitive Systems: A Case Study of Color Category Boundaries. Man-Machine Interactions,3, 385393(2014)

4. E. Gibson, R. Futrell, J. Jara-Ettinger et al. Color naming across languages reflects color use. Proc Natl Acad Sci USA,114, 10785-10790(2017)

5. S. C. Levinson Language and space. Annual Review of Anthropology,25(1), 353-382 (1996)

6. S. C. LevinsonSpace in language and cognition: Explorations in cognitive diversity. Cambridge University Press,5, (2003)

7. A. Majid, M. Bowerman, S. Kita et al. Can language restructure cognition? The case for space. Trends Cogn Sci,8, 108-114(2004) 
8. D. B. M.Haun, C. J. Rapold,G. Janzen, S. C. Levinson Plasticity of human spatial cognition: Spatial language and cognition covary across cultures. Cognition,119, 70$80(2011)$

9. G. Lupyan, R. Dale Why are there different languages? The role of adaptation in linguistic diversity. Trends Cogn Sci,20, 649-660(2016)

10. R. D. Ladd, S. G. Roberts, D. Dediu Correlational studies in typological and historical linguistics. Annu. Rev. Linguist, 1, 221-241(2015)

11. M. Litovskaya Adult children's writer P. P. Bazhov: conflict of editors. Children's Readings, 2, 243-254(2014)

12. B. Smith, D.M.Mark Ontology with human subjects testing: an empirical investigation of geographic categories. American Journal of Economics and Sociology,58(2), 245272(1999)

13. S. C. Levinson, D. P. WilkinsGrammars of Space: Explorations in Cognitive Diversity,(Cambridge: Cambridge University Press,2006)

14. G. SenftProlegomena to a Kilivila grammar of space. In S. C. Levinson \& D. P. Wilkins (eds.).Grammars of Space: Explorations in Cognitive Diversity, 206-229. (Cambridge: Cambridge University Press, 2006)

15. K. H.BassoWestern Apache place-name hierarchies. In: Tooker, E,(1984)

16. E.HunnTzeltal Folk Zoology: The Classification of Discontinuity in Nature, (Academic Press, New York,1977)

17. L.Hercus, F.Hodges, J. Simpson (Eds.) The Land Is a Map: Placenames of Indigenous Origin in Australia, (Pandanus Books, Canberra,2002)

18. N.Burenhult, S. C. Levinson Language and landscape: a cross-linguistic perspective. Language Sciences, 30(2-3), 135-150 (2008)

19. A. N. H. MansouriSemantic field theory and the teaching of English vocabulary with special reference to Iraqi secondary schools, (University of Sheffield,1985)

20. Ch.Gao, B. Xu The Application of Semantic Field Theory to English Vocabulary Learning. Theory and Practice in Language Studies,3(11), 2030-2035(2013)

21. A. LehrerSemantic Fields and Lexical Structure,(North-Holland, 1974)

22. J. LyonsSemantics, (Cambridge University Press, 1977)

23. G. Stern Meaning and Change of Meaning, with Special Reference to the English Language,(Bloomington-London: Indiana University Press,1931)

24. G. A.

Kleparski, A.

Rusinek, Thetraditionoffieldtheoryandthestudyoflexicalsemanticchange. Studia Anglica Resovie nsia, 4, 188-205(2007)

25. G.A. Kleparski Lexical mobility: Some problems of its justification and interpretation. KwartalnikNeofilologiczny,30, 3-12(1983)

26. L. S. VygotskyThought and language,(Cambridge, MA: MIT Press,1986) 
27. L. S. Vygotsky Play and Its Role in the Mental Development of the Child. Soviet Psychology,5, 6-18(1967)

28. R. de BusserThe influence of social, cultural, and natural factors on language structure: An overview. In Rik De Busser, Randy J. LaPolla (eds.). Language Structure and Environment: Social, Cultural, and Natural Factors, 1-28 (Publisher: John Benjamins,2015)

29. I. F. Collard, R. A. Foley Latitudinal patterns and environmental determinants of recent human cultural diversity: do humans follow biogeographical rules? Evol. Ecol. Res., 4, 371-383 (2002)

30. W. J. SutherlandParallel extinction risk and global distribution of languages and species. Nature, 423, 276-279(2003)

31. C. Everett Evidence for direct geographic influences on linguistic sounds: The case of ejectives. PLoS ONE,8(6), (2013)

32. R. A. Foley The evolutionary ecology of linguistic diversity in human populations. In Jones M. (ed.).Traces of ancestry: studies in honour of Colin Renfrew,6171(Cambridge: McDonald Institute Monographs,2004)

33. T. Honkola et al. Evolution within a language: environmental differences contribute to divergence of dialect groups. BMC Evolutionary Biology, 18,(2018)

34. S. Lee, T. Hasegawa Oceanic barriers promote language diversification in the Japanese Islands. J Evol Biol.,27, 1905-1912(2014)

35. F. Hinskens, P. Auer,P. Kerswill The study of dialect convergence and divergence: conceptual and methodological considerations. In: Auer P, Kerswill P, Hinskens F. (eds.). Dialect change: convergence and divergence in European languages,148.(Cambridge: Cambridge University Press,2005)

36. D. J. FutuymaEvolution. 2nd ed. (Sunderland: Sinauer,2009)

37. C.Lexer, S.Mangili, E.Bossolini, F.Forest, K. N.Stölting, P. B. Pearman et al. 'Next generation' biogeography: towards understanding the drivers of species diversification and persistence. J Biogeogr., 1013-1022(2013)

38. P. Auer The Geography of Language: Steps toward a New Approach. FRAGL,16, 139(2013)

39. J.-L. uis. Mendívil-Giró Why Don't Languages Adapt to Their Environment? Frontiers in Communication, 3, 24 (2018)

40. L. Yu. Stepanova The adjective STONE in the tales of P. P. Bazhov. The world of the Russian word,1, 22-28 (2019)

41. The Russian National Corpus, (2020)

42. N. A. Potapova Allocation of paremias with the lexeme "stone" in the texts of the The Russian National Corpus. Philological sciences. Questions of theory and practice, $\mathbf{1}$, 131-135(Tambov: Diploma. No. 2 (80), 2018)

43. A. M. Karminsky, A. A. PolozovEncyclopedia of ratings: economy, society, sport. 2nd ed. (Moscow: FORUM: INFRA-M, 2016) 
44. A. V. Rudakova, I. A. Sternin Psycholinguistic experiment and description of word semantics. Psycholinguistic questions, 27, 194-208 (2016)

45. A. V. Rudakova, I. A. SterninPsycholinguistic significance and its description,("Lambert", 2011)

46. Psycholinguistic Explanatory Dictionary of the Russian Language. Gender values (with comments) / Eds. I.A. Sternin, A.V. Rudakov, 10(1),(Voronezh: RITM LLC.,2019)

47. O.E. Vinogradova, I.A. SterninPsycholinguistic techniques in describing the semantics of a word. Monograph,(Voronezh: Istoki publishing house,2016)

48. Ushakov'sDictionary, (1935-1940)

49. Ozhegov's Explanatory Dictionary, (2020)

50. New dictionary of foreign words,.(2009)

51. Etymological Dictionary of the Modern Russian Language. 2010/ Ed. A.K. Shaposhnikov: in 2 volumes. The etymological online dictionary of the Russian language by Max Vasmer, 1,(Moscow: Flint: Science,2020)

52. M. R. LvovDictionary of Russian antonyms: More than 2,000 antonymous pairs. Ed. L.A. Novikova. 2nd ed.,(Moscow: Rus. Yaz,1984)

53. Dictionary of Synonyms of the Russian Language. Practical guide. Ed. Z.E. Aleksandrova,(Moscow: Russian language, 2011)

54. Diploma. $R U,(2020)$

55. Dictionary of Synonyms and Antonyms of the Modern Russian Language. 50,000 words, (Moscow: "Adelant", 2014)

56. V.N. TrishinASIS Dictionary of Synonyms,(2013)

57. A. A. Konovalov Placer gold of the Manya in the Subpolar Urals.Notes of the Mining Institute.167(2), 26-28(2006)

58. O. G. Zgurskaya Mythological and real world in the drama of Alexander Pushkin "Mermaid". Questions of cognitive linguistics,4, 85-91 (2014)

59. P.P. Bazhov Malachite box,(2007)

60. J.M. Sishchuk, I.G. Gerasimova, M.V. Goncharova Anthropocentric world picture in German and English geological and mining metaphoric terms. Innovation-Based Development of the Mineral Resources Sector: Challenges and Prospects - 11th conference of the Russian-German Raw Materials, 555-560(2019)

61. O. V. BorchwaldtDictionary of the gold industry of the Russian Empire, (Moscow: Russian way, 1998)

62. I.A. Golovanov The problem of becoming a master in the stories of A. Platonov and the tales of P. Bazhov. Bulletin of the Chelyabinsk State University,37(328), 129-132 (2013)

63. M.I. Mikeshin Social metaphysics of the Strugatsky brothers. Bulletin of the Leningrad State University named after A.S. Pushkin,4(2), 243-253(2015) 
64. The Big Explanatory Dictionary of the Russian Language. Ed. S.A. Kuznetsova, (2014) 